\title{
Noonan Syndrome: Comparing Mutation-Positive with Mutation-Negative Dutch Patients
}

\author{
E.A. Croonen ${ }^{a}$ W. Nillesen ${ }^{b} \quad$ C. Schrander ${ }^{c} \quad$ M. Jongmans ${ }^{b} \quad$ H. Scheffer ${ }^{b}$ \\ C. Noordam ${ }^{a}$ J.M.T. Draaisma ${ }^{a}$ I. van der Burgt ${ }^{b}$ H.G. Yntema ${ }^{b}$ \\ Departments of a Pediatrics and ${ }^{\mathrm{b}}$ Human Genetics, Radboud University Nijmegen Medical Centre, Nijmegen, and \\ 'Department of Human Genetics, Maastricht University Medical Centre, Maastricht, The Netherlands
}

\section{Key Words}

Facial characteristics $\cdot$ Congenital heart defects · Noonan syndrome $\cdot$ RAS-MAPK pathway $\cdot$ RASopathies

\begin{abstract}
Noonan syndrome (NS) is an autosomal dominant disorder characterized by facial dysmorphisms, short stature and congenital heart defects. The disorder is genetically heterogeneous and shows clinical overlap with other RASopathies. These syndromes are caused by mutations in a variety of genes leading to dysregulation of the RAS-MAPK pathway: PTPN11, KRAS, SOS1, RAF1, CBL, SHOC2, NRAS, BRAF, MAP2K1, MAP2K2, HRAS, NF1 and SPRED1. In this study, we conduct a genotype-phenotype analysis of 33 patients with a clinical diagnosis of NS without a PTPN11 mutation. Mutation analysis of the genes involved in RASopathies was performed, except for NF1 and SPRED1. In 14 (42\%) NS patients, a mutation was found, 7 (21\%) had a mutation in SOS1, 3 (9\%) in RAF1 and 1 (3\%) in KRAS, MAP2K2, BRAF and SHOC2 each. The phenotype of these mutation-positive cases corresponded to that described in the literature. In the cases with a BRAF and MAP2K2 mutation, the diagnosis cardio-facio-cutaneous syndrome was made. The patient with the SHOC2 mutation had features compatible with 'Noonan-like syn-
\end{abstract}

drome with loose anagen hair'. Three major clinical features of NS - a typical face, short stature and a pulmonary valve stenosis - were less frequently present in the group without a mutation. Missense mutations in genes encoding proteins of the RAS-MAPK pathway cause NS. The 3 major clinical features of NS were less frequently present in the mutationnegative patients, which stresses the importance of the syndrome-specific symptoms of the face, heart and short stature in NS. However, all mutation-negative cases met the NS criteria, indicating that the involvement of novel genes is to be expected.

Copyright $\odot 2013$ S. Karger AG, Basel

Noonan syndrome (NS) is a well-known autosomal dominant disorder with an estimated incidence of 1:1,000-2,500 live births [Nora et al., 1974]. Excellent reviews of NS have been published and have commented on clinical and molecular findings [Noonan, 1994; Allanson, 2007; Jorge et al., 2009].

The cardinal features of NS are characteristic facies, short stature, congenital heart defects, skeletal abnormalities, cryptorchidism, and variable development delay [Allanson, 1987; Sharland et al., 1992; Noonan, 1994]. The facial dysmorphisms show considerable change with

\section{KARGER}

E-Mail karger@karger.com

www.karger.com/msy
(C) 2013 S. Karger AG, Basel

1661-8769/13/0045-0227\$38.00/0 
age, being more prominent in childhood and less conspicuous in the adult [Allanson et al., 1985]. Congenital heart defects occur in $66-87 \%$ of cases [Allanson, 1987; Marino et al., 1999; Bertola et al., 2000; Croonen et al., 2008]. The most common cardiac anomaly is a stenosis of the pulmonary valve, which may be dysplastic (3274\%). Hypertrophic cardiomyopathy occurs in 8-33\% [Allanson, 1987; Sharland et al., 1992; Ishizawa et al., 1996; Marino et al., 1999; Bertola et al., 2000; Zenker et al., 2004; Shaw et al., 2007; Croonen et al., 2008]. The electrocardiogram (ECG) of NS patients commonly shows left axis deviation, small $\mathrm{R}$ waves in the left precordial leads, abnormal Q waves, and a wide QRS complex [Celermajer et al., 1968; Ehlers et al., 1972; Sanchez-Cascos, 1983; Bertola et al., 2000; Croonen et al., 2008].

NS is genetically heterogeneous and shows a considerable clinical overlap with Costello syndrome, LEOPARD syndrome (multiple lentigines - ECG conducting abnormalies - ocular hypertelorism - pulmonic steonsis - abnormal genitalia - retardation of growth - sensorineural deafness) and cardio-facio-cutaneous (CFC) syndrome. Neurofibromatosis type 1 (NF1) and Legius syndrome have more specific features: café-au-lait spots in Legius syndrome (SPRED1 gene) and neurofibromas in NF1 (NF1 gene) [Barker et al., 1987; Brems et al., 2007]. These syndromes all belong to RASopathies, a specific class of developmental disorders caused by germline mutations in genes encoding proteins of the Ras-mitogen-activated protein kinase (RAS-MAPK) pathway [Tidyman and Rauen, 2009]. About $50 \%$ of known NS cases have a gain-of-function mutation in the PTPN11 gene [Tartaglia et al, 2001, 2002]. Heterozygous gain-of-function mutations in other genes encoding proteins of the RAS-MAPK pathway have also been identified in NS and other RASopathy syndromes: KRAS [Carta et al., 2006; Schubbert et al., 2006], SOS1 [Roberts et al., 2007; Tartaglia et al., 2007], RAF1 [Pandit et al., 2007; Razzaque et al., 2007], MAP2K1 [Nava et al., 2007], BRAF [Niihori et al., 2006], SHOC2 [Cordeddu et al., 2009], NRAS [Cirstea et al., 2010], and CBL [Martinelli et al., 2010]. Two genes are only associated with Costello and CFC syndrome, respectively, HRAS [Aoki et al., 2005] and MAP2K2 [Rodriguez-Viciana and Rauen, 2008].

The purpose of this study was to identify the disease causing mutation in 33 patients with a clinical diagnosis of NS without a PTPN11 gene mutation, by analysis of 10 genes involved in the RASopathies. The mutation-positive NS patients are compared to known cases from literature and to those with an unknown genetic cause, with the aim to ascertain whether there are important clinical differences between the groups.

\section{Patients and Methods}

Patients

We included 33 patients with Noonan syndrome, clinically diagnosed at one tertiary center using the cardinal features delineated by van der Burgt et al. [1994]. Mutation analysis of the PTPN11 gene was negative in all cases.

\section{Electrocardiogram}

A pediatric cardiologist who was blinded for mutation status and the presence of a cardiac abnormality judged the ECG. The ECG was scored on 4 characteristic ECG findings [Park, 1996]:

(1) Left axis deviation: the QRS axis less than the lower limit of normal for the patient's age.

(2) Small $\mathrm{R}$ waves in the left precordial leads: the R/S ratio in lead V6 is lower than the lower limits of normal and the $\mathrm{R}$ wave voltage in leads V5 and V6 is less than $50 \%$ of the mean.

(3) Wide QRS-complex: a QRS duration of more than $0.08 \mathrm{~s}$ under the age of 3 years, above $0.10 \mathrm{~s}$ between 3 and 12 years and above the upper limit for QRS duration of $0.12 \mathrm{~s}$ from 12 years on.

(4) Abnormal Q wave: the Q voltage is greater than the upper limit of normal and wider than $0.04 \mathrm{~s}$.

\section{DNA Analysis}

DNA of all patients was tested by Sanger sequencing in a routine DNA diagnostic setting for mutations in the coding regions of the genes PTPN11, KRAS, HRAS, NRAS, BRAF, RAF1, SOS1, $M A P 2 K 1, M A P 2 K 2, S H O C 2$, and $C B L$ (for primer sequences and PCR conditions see online supplementary material, www. karger.com/doi/10.1159/000350686). Classification of sequence variants was according to the CMGS practice guidelines for the interpretation and reporting of unclassified variants in clinical molecular genetics (http://www.cmgs.org/BPGs/pdfs\%20current\%20bpgs/UV\%20GUIDELINES\%20ratified.pdf). Only mutations classified as unclassified variants 3 or 4 were reported. The study was performed according the regulations of the local medical ethical committee.

\section{Statistical Analysis}

The data were analyzed with SPSS, version 16.0. Because of the small number of patients only descriptive analysis was performed.

\section{Results}

\section{Mutation-Positive NS Patients}

In figure 1, the distribution of the different genes involved in our NS cohort is shown. Tables 1 and 2 show the mutations and their patient characteristics.

In 14 of the 33 NS patients without a mutation in PTPN11 (42\%), a mutation in one of the other 10 genes that were analyzed could be identified.

Seven patients had a SOS1 mutation (21\%). Six of these mutations were described earlier in other NS cases, namely c.797C >A (p.Thr266Lys), c.806T >C (p.Met269Thr), c.806T $>$ G (p.Met269Arg), c.1644T $>$ C (p.Ser548Arg), c.1656G >C (p.Arg552Ser), and c.2104T>C (p.Tyr702His) 


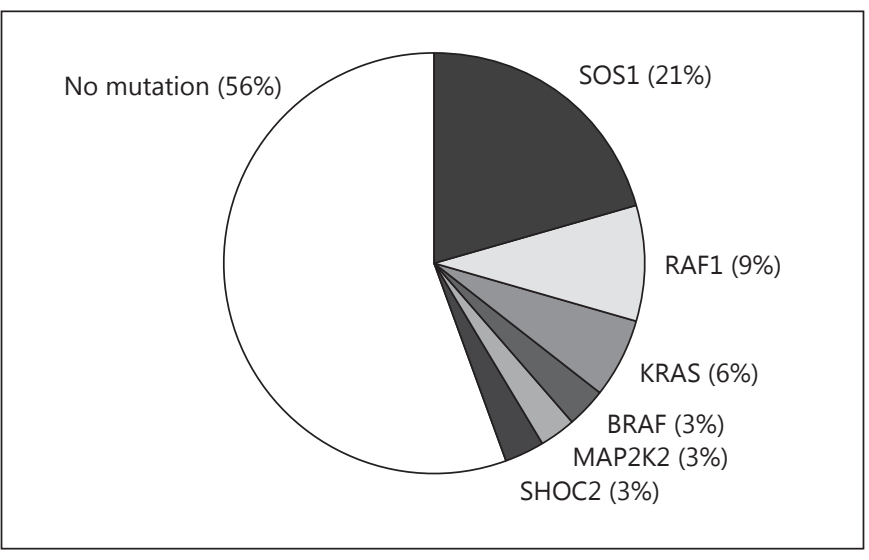

Fig. 1. Distribution of the different genes involved in our cohort of patients with a clinical diagnosis of Noonan syndrome.

[Roberts et al., 2007; Tartaglia et al., 2007; Zenker et al., 2007]. The mutations c.797C $>$ A (p.Thr266Lys) and c.2104T $>\mathrm{C}$ (p.Tyr702His) were found to be de novo in the patient, whereas the c. $806 \mathrm{~T}>\mathrm{C}$ (p.Met269Thr) mutation was present in 2 affected brothers, and the c. $1656 \mathrm{G}>\mathrm{C}$ (p.Arg552Ser) mutation was inherited from the affected mother. For the other patients with a previously described SOS1 mutation, no family history of NS was noted, but family studies have not been performed. One novel de novo mutation was identified: c.2183A $>$ T (p.Lys728Ile), located in the REM domain of the SOS1 gene. The clinical features of this patient have been described elsewhere [Jongmans et al., 2010].

Three patients had a RAF1 mutation (9\%). These mutations, c.781C $>$ G (p.Pro261Ala), c.1457A $>$ G (p.Asp486Gly) and c.1837C >G (p.Leu613Val) were described earlier in NS patients [Pandit et al., 2007; Razzaque et al., 2007]. For none of these patients parental studies could be performed, but no family history of NS was described.

One patient had a KRAS mutation (3\%): c.40G $>$ A (p.Val14Ile). The same mutation was present in her affected twin brother, but the parents did not have the mutation. This mutation is previously described as a pathogenic mutation by Schubbert et al. [2006].

In one case (3\%) a de novo BRAF mutation, c.736G $>C$ (p.Ala246Pro), was identified. This mutation was published by Nava et al. [2007] and Niihori et al. [2006] in $\mathrm{CFC}$ patients. The clinical features of our patient are consistent with CFC syndrome (fig. 2).

In one patient (3\%) we identified a MAP $2 K 2$ mutation, c.401A $>\mathrm{G}$ (p.Tyr134Cys), which was first published by Rodriguez-Viciana et al. [2008] in a CFC patient. The mutation was found in a 20-year-old man with an NS phenotype. This patient was born with a pulmonary valve stenosis and cryptorchidism. He had neonatal feeding difficulties and a developmental delay. At 20 years, his height was $1.95 \mathrm{~m}$ and weight $82 \mathrm{~kg}$. He had multiple pigmented nevi and easy bruising. Neuropsychological testing yielded an IQ of 70. The patient presented with characteristic facial features including hypertelorism and low set ears (fig. 3). One half-sister died after 9 months, who had a severe pulmonary valve stenosis. The father is clinically affected, but no mutation analysis has been done.

In one patient (3\%) we found the previously reported pathogenic mutation c. $4 \mathrm{~A}>\mathrm{G}$ (p.Ser2Gly) in the SHOC2 gene. This mutation was first reported by Cordeddu et al. [2009]. The parents were not available for testing.

\section{Mutation-Positive versus Mutation-Negative Patients}

A typical dysmorphic appearance was seen most in mutation-positive patients (93\% (13/14) vs. 74\% (14/19)). Small stature (height $<-2$ SD) was observed more often in mutation-positive patients $(79 \%(11 / 14)$ vs. $63 \%$ $(12 / 19))$. Also heart defects were more prevalent in mutation-positive patients $(79 \%(11 / 14)$ vs. $56 \%(10 / 18))$, with pulmonary stenosis as most common $(64 \%(9 / 14)$ vs. $39 \%(7 / 18))$. Other heart defects were more frequent in the mutation-negative group $(33 \%(6 / 18)$ vs. $14 \%$ $(2 / 14))$. NS patients with a mutation had an aberrant ECG twice as often as NS patients without a mutation (46\% $(5 / 11)$ vs. $23 \%(3 / 13))$. Figure 4 shows a NS patient without a known mutation.

\section{Discussion}

\section{Analysis}

Because of the small cohort, we only applied descriptive analysis. When comparing the characteristics of all NS patients known in literature, no evident differences were found [Allanson, 1987, 2007; Sharland et al., 1992; Croonen et al., 2008].

All mutation-positive cases fulfill the criteria declined by van der Burgt et al. [1994] for the diagnosis of NS. We found a SOS1 mutation in 7 out of $33(21 \%)$ patients, analogous to the literature (17-28\%) [Roberts et al., 2007; Tartaglia et al., 2007; Zenker et al., 2007]. In line with these same reports, we found a similar spectrum of congenital heart defects with a high prevalence of pulmonary stenosis, facial characteristics (ptosis, downslanted palpebral fissures and low set ears), curly hair and pectus deformities. Two reports identified a high frequency (50-58\%) of ecto- 
Table 1. Clinical characteristics of patients with Noonan syndrome, grouped by mutation status and type

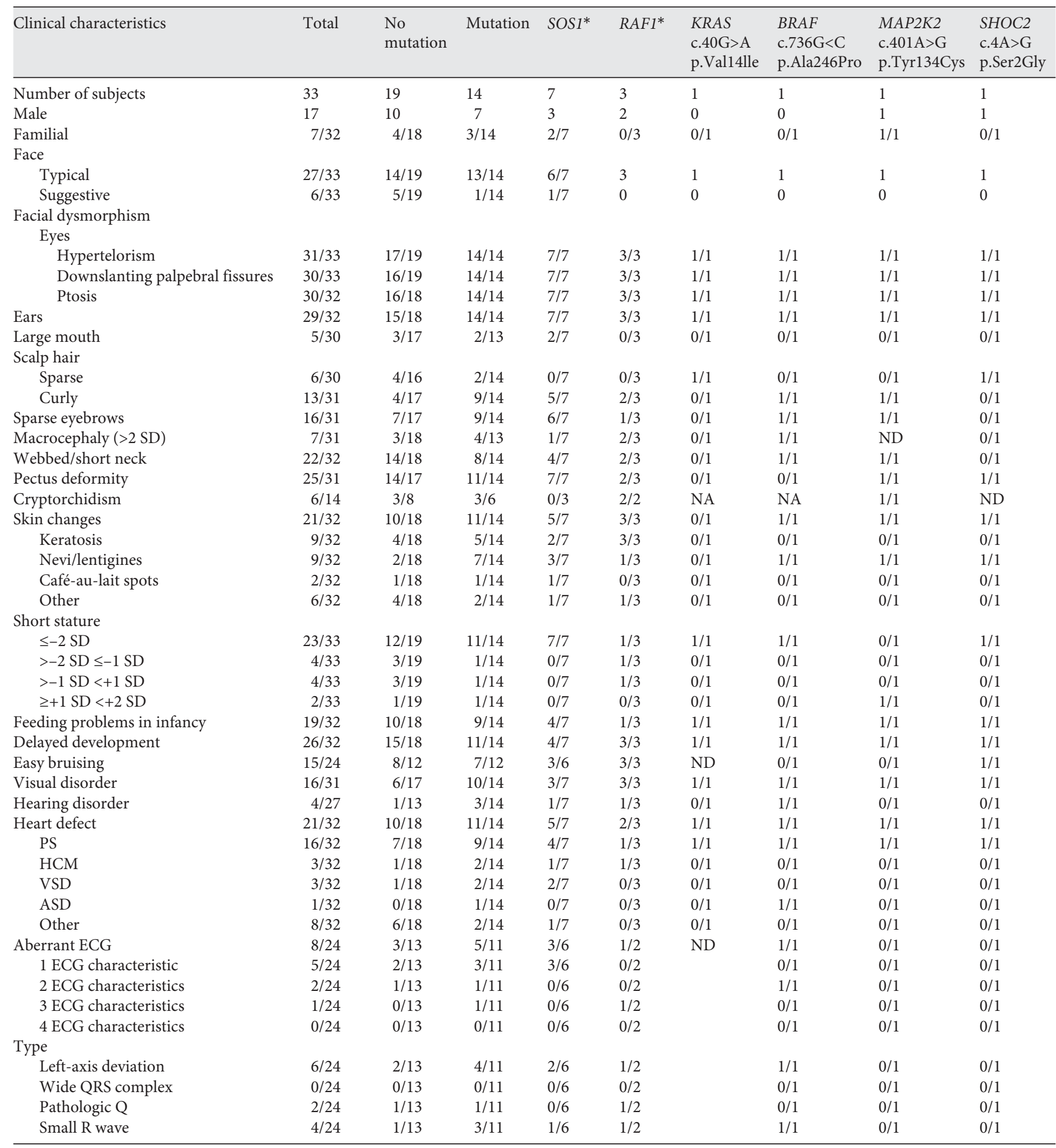

PS = Pulmonary stenosis; HCM = hypertrophic cardiomyopathy; VSD = ventricular septal defect; ASD = atrial septal defect; ND = not determined; $\mathrm{NA}=$ not applicable, female patient.

* For details for each patient, see table 2 . 
Table 2. Characteristics of individual patients with a SOS1 or RAF1 mutation

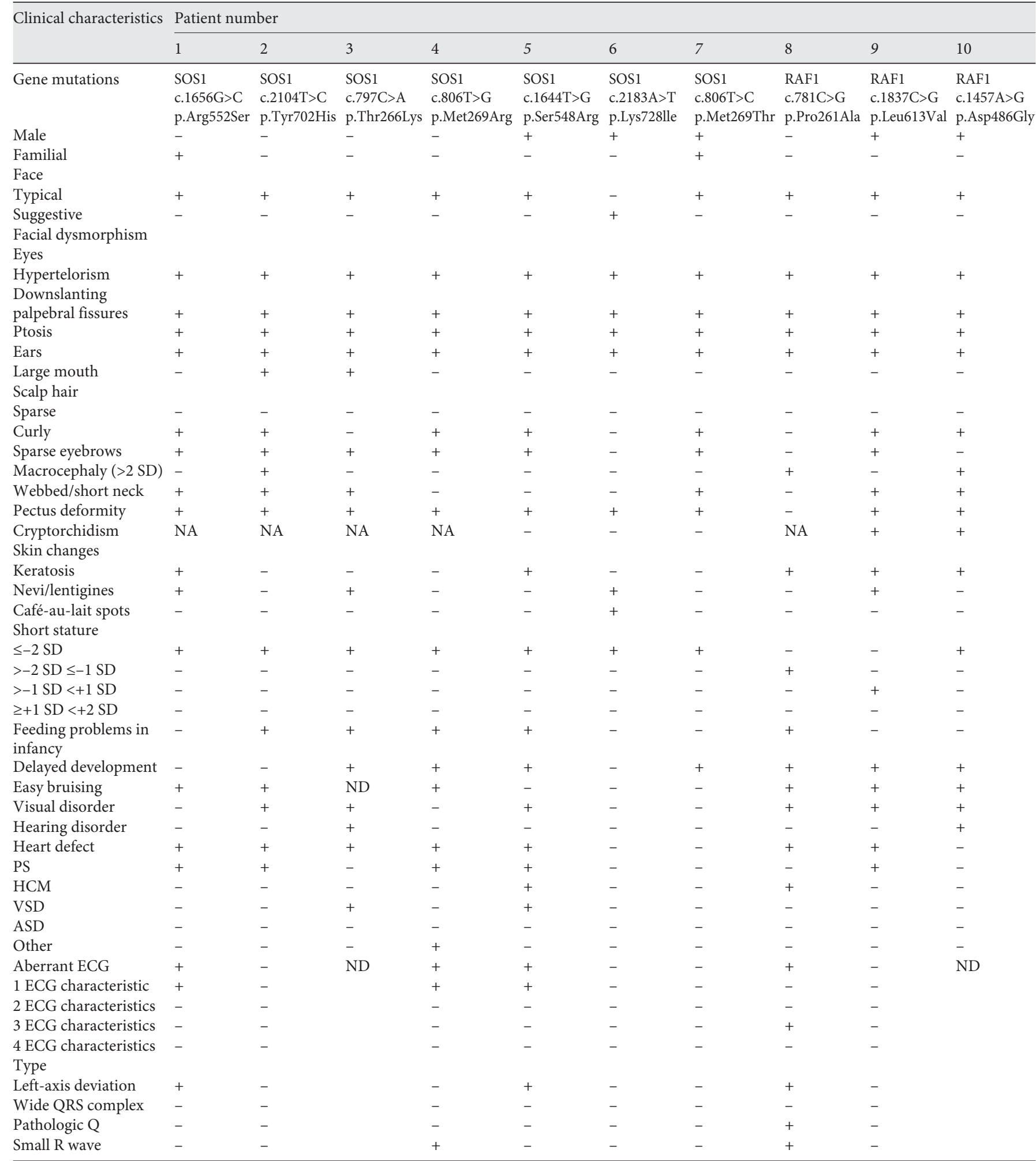

For abbreviations, see table 1. 
Fig. 2. Clinical features of the patient with the BRAF mutation, consistent with CFC syndrome.

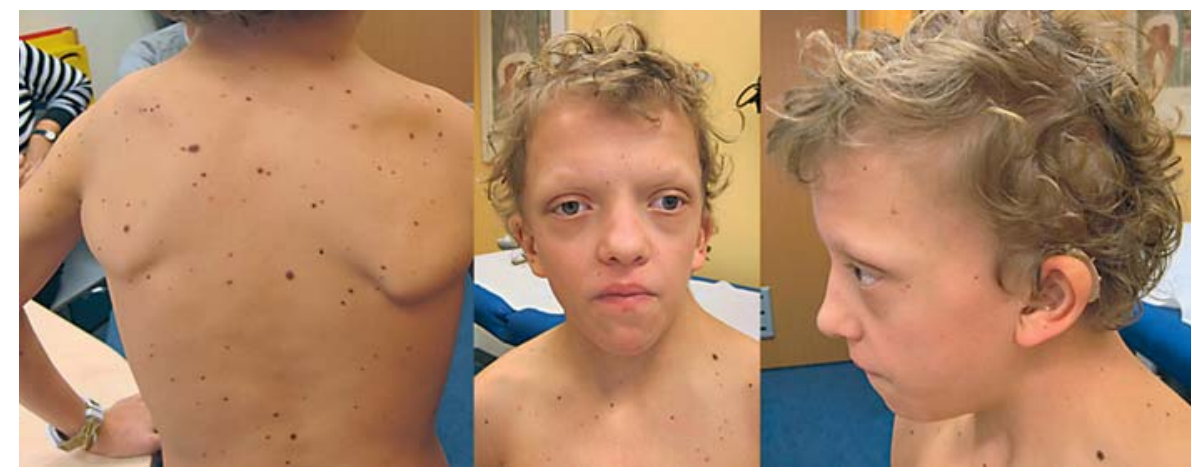

Fig. 3. Clinical features of the patient with the MAP2K2 mutation, consistent with CFC syndrome.

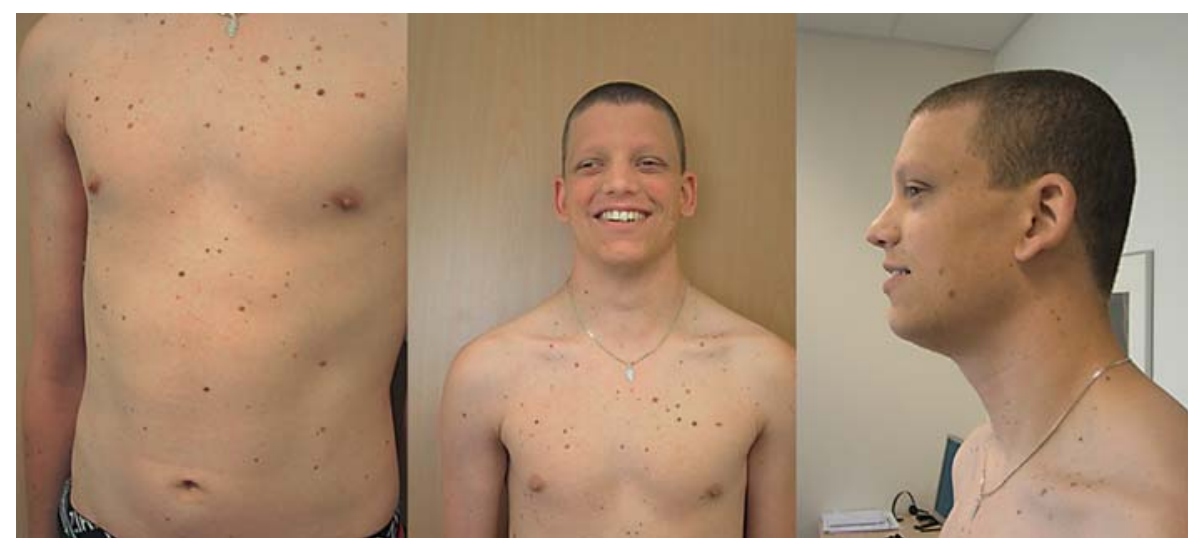

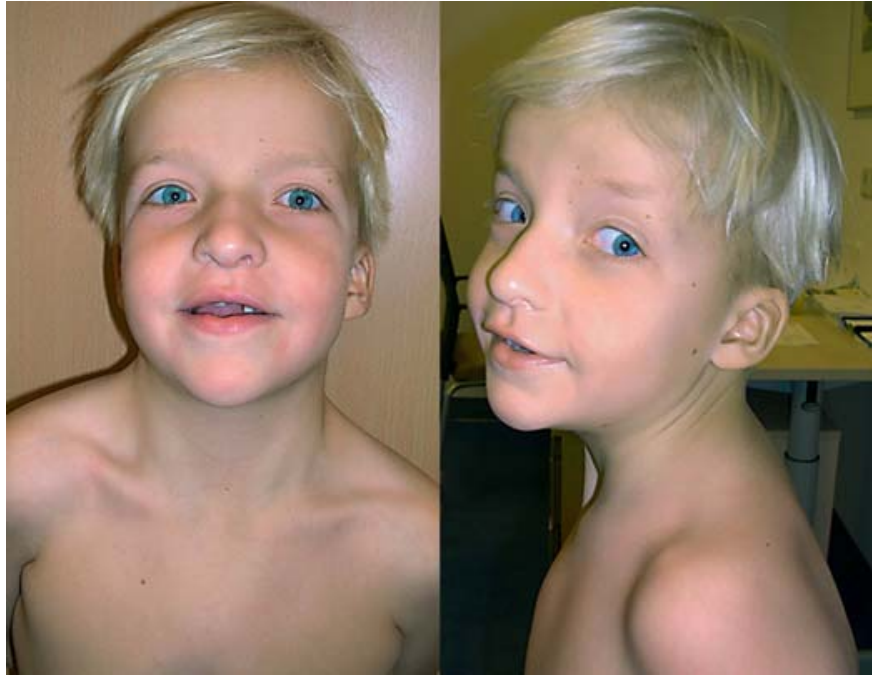

Fig. 4. Clinical features of one of the mutation-negative patients, who still meet the clinical criteria for Noonan syndrome. dermal anomalies which is not the case in our study $(2 / 7$; 29\%) [Tartaglia et al., 2007; Zenker et al., 2007]. Interestingly, we noticed a height below -2 SD in all NS patients with a SOS1 mutation (compared to $13-52 \%$ in literature), mental retardation and/or need for special education in $57 \%(4 / 7)$ (compared to 6-27\% in literature), macrocephaly in $14 \%(1 / 7)$ (compared to $56 \%$ in literature), and cryptorchidism in none of the patients (ref. 45-50\%) [Roberts et al., 2007; Tartaglia et al., 2007; Zenker et al., 2007]. The phenotypic differences between the SOS1 positive patients in this study and the previously reported cases are likely to be explained by differences in the way the patients are included, selected, characteristics are described as well a variation in the included type of mutations.

We found KRAS mutations in 1 out of 33 (3\%) patients, analogous to the literature [Carta et al., 2006; Schubbert et al., 2006]. These reports describe patient characteristics comparable to our patient. Several cases described in the literature present a severe NS condition, eventually with features overlapping Costello syndrome and CFC syndrome. 
We observed a RAF1 mutation in 3 of 33 patients (9\%), analogous to the literature (8.4-17\%) [Pandit et al., 2007; Razzaque et al., 2007]. In line with these same reports, we found a similar spectrum of characteristics. However, they demonstrate that $R A F 1$ is the major gene associated with hypertrophic cardiomyopathy in NS (76-82\%). In our cohort, only one NS patient with an RAF1 mutation had hypertrophic cardiomyopathy.

$B R A F$ mutations are predominantly described in CFC syndrome [Niihori et al., 2006; Nava et al., 2007; Nystrom et al., 2008]. However, BRAF mutations are also found in NS [Sarkozy et al., 2009] and LEOPARD syndrome [Sarcozy et al., 2008]. In our cohort, we found one mutation in BRAF. Using our criteria, we misdiagnosed NS in this patient at early age. The clinical features of the patient with the BRAF mutation are consistent with CFC syndrome (table 1, fig. 2). She had the typical facial features, nevi, developmental delay, short stature, hearing and visual disorders, and a valvular pulmonary stenosis with an atrial septal defect. Her ECG registration showed left axis deviation and small $\mathrm{R}$ waves in left precordial leads.

Mutations in the MAP2K2 gene are so far only described in patients with CFC syndrome [Rodriguez-Viciana and Rauen, 2008; Koudava et al., 2009]. Our patient was first diagnosed with NS. In retrospect, the presence of multiple pigmented nevi and an IQ of 70 do also suspect CFC syndrome in this patient as well (fig. 3). However, a height of almost $2 \mathrm{~m}$ is a striking finding in CFC patients and in a broader context, in all the related disorders known as RASopathies.

In 2009, Cordeddu et al. [2009] published the involvement of the c. $4 \mathrm{~A}>\mathrm{G}$ (p.Ser2Gly) mutation in SHOC2 in 25 patients with the diagnosis Noonan-like syndrome with loose anagen hair. They revealed a consistent phenotype with characteristic craniofacial appearance (macrocephaly, a prominent forehead, hypertelorism, ptosis, low set and posteriorly rotated ears, and loose anagen hair with sparse and/or absent scalp hair), pectus anomalies and a darkly pigmented skin with eczema or ichthyosis. They also showed cognitive deficits, reduced growth, frequently associated with growth hormone deficiency, and cardiac anomalies (pulmonary stenosis and hypertrophic cardiomyopathy). Some of these characteristics were seen in our patient with a SHOC2 mutation, such as the craniofacial appearance, sparse and thin scalp hair, short stature, intellectual disability and hyperpigmented skin. Macrocephaly and hyperactive behavior were not observed. Growth hormone values were never measured; however, his adult height was $167.5 \mathrm{~cm}(<-2$ SD). According to these characteristics, these patients had clinical fea- tures that were compatible with Noonan-like syndrome with loose anagen hair.

\section{The RASopathies}

Noonan syndrome, LEOPARD syndrome, CFC syndrome, and Costello syndrome are - together with NF1 and Legius syndrome - related disorders known as RASopathies [Tidyman and Rauen, 2009]. Several genes involved in the RAS-MAPK pathway are associated with these syndromes. Nyström et al. [2008] concluded in their study that the molecular and clinical overlap between CFC and NS is more complex than previously suggested and that these 2 syndromes might even represent allelic disorders. Despite attempts made to discriminate overlapping RASopathies, such as phenotypic lists of overlap between NS, CFC and CS presented by Roberts et al. [2006], it will be very hard to diagnose the 'right syndrome' in all patients. All the NS patients included in our study fulfill the criteria of van der Burgt et al. [1994]. However, in retrospect, 2 of them were diagnosed as having CFC. Based on these findings, we believe that the sensitivity of the criteria of van der Burgt is low because patients with CFC also fulfill these criteria, which can be explained by overlap of clinical characteristics which are used as criteria for diagnosis [van der Burgt et al., 1994; Kavamura et al., 2002]. On the other hand, the specificity is high, which means no NS patient will be missed according to the criteria. We believe the discrepancy in diagnosis will continue because of these significant clinical overlaps and the large intra- and interfamilial variability of expression in each of the RASopathies.

We had no reasons to change the clinical diagnosis in the other patients of our cohort. In the group of mutation-negative patients, all 3 major clinical features of NS typical face, short stature and a pulmonary valve stenosis - were less frequently present. This observation stresses the importance of these 3 major features for the diagnosis of NS. However, all mutation-negative cases still meet the clinical criteria for NS. The facial features of one of these patients are shown in figure 4. Since in several typical Noonan cases the underlying genetic defect has not yet been identified, the involvement of novel genes is to be expected.

\section{Acknowledgements}

The authors are grateful to Kim van der Donk for expert technical assistance and to all patients together with their families for participation. 


\section{References}

-Allanson JE: Noonan Syndrome. J Med Genet 24: Ishizawa A, Oho S, Dodo H, Katori T, Homma SI: 9-13 (1987).

Allanson JE: Noonan Syndrome. Am J Med Genet 145:274-279 (2007).

Allanson JE, Hall JG, Hughes HE, Preus M, Witt RD: Noonan syndrome: the changing phenotype. Am J Med Genet 21:507-514 (1985).

-Anastasaki C, Estep AL, Marais R, Rauen KA, Patton EE: Kinase-activating and kinase-impaired cardio-facio-cutaneous syndrome alleles have activity during zebrafish development and are sensitive to small molecule inhibitors. Hum Mol Genet 18:2543-2554 (2009).

-Aoki Y, Niihori T, Kawame H, Kurosawa K, Ohashi $\mathrm{H}$, et al: Germline mutations in HRAS proto-oncogene cause Costello syndrome. Nat Genet 37:1038-1040 (2005).

- Barker D, Wright E, Nguyen K, Cannon L, Fain P, et al: Gene for von Recklinghausen neurofibromatosis is in the pericentromeric region of chromosome 17. Science 236:1100-1102 (1987).

-Bertola DR, Kim CA, Sugayama SMM, Albano LM, Wagenführ J, et al: Cardiac findings in 31 patients with Noonan's syndrome. Arq Bras Cardiol 75:409-412 (2000).

-Brems H, Chmara M, Sahbatou M, Denayer E, Taniguchi K, et al: Germline loss-of-function mutations in SPRED1 cause a neurofibromatosis 1-like phenotype. Nat Genet 39:11201126 (2007).

- Carta C, Pantaleoni F, Bocchinfuso G, Stella L, Vasta I, et al: Germline missense mutations affecting KRAS isoform B are associated with a severe Noonan syndrome phenotype. Am J Hum Genet 2006;79:129-135 (2006).

-Celermajer JM, Bowdler JD, Cohen DH: Pulmonary stenosis in patients with the Turner phenotype in the male. Am J Dis Child 116:351358 (1968).

-Cirstea IC, Kutsche K, Dvorsky R, Gremer L, Carta C, et al: A restricted spectrum of NRAS mutations causes Noonan syndrome. Nat Genet 42:27-29 (2010).

-Cordeddu V, Di Schiavi E, Pennacchio LA, Ma'ayan A, Sarkozy A, et al: Mutation of SHOC2 promotes aberrant protein N-myristoylation and causes Noonan-like syndrome with loose anagen hair. Nat Genet 41:10221026 (2009).

Croonen EA, van der Burgt I, Kapusta L, Draaisma JM: Electrocardiography in Noonan syndrome PTPN11 gene mutation - phenotype characterisation. Am J Med Genet A 146:350353 (2008).

- Ehlers KH, Engle MA, Levin AR, Deely WJ: Eccentric ventricular hypertrophy in familial and sporadic instances of 46 XX, XY Turner phenotype. Circulation 45:639-652 (1972).

Gelb BD, Tartaglia M: Noonan syndrome and related disorders: dysregulated RAS mitogen activated protein kinase signal transduction. Hum Mol Genet 15:220-226 (2006). Cardiovascular abnormalities in Noonan syndrome: the clinical findings and treatments. Acta Paediatr Jpn 38:84-90 (1996).

Jongmans MC, Hoogerbrugge PM, Hilkens L, Flucke U, van der Burgt I, et al: Noonan syndrome, the SOS1 gene and embryonal rhabdomyosarcoma. Genes Chromosomes Cancer 49:635-641 (2010).

Jorge AA, Malaquias AC, Arnhold IJ, Mendonca BB: Noonan syndrome and related disorders: a review of clinical features and mutations in genes of the RAS/MAPK pathway. Horm Res 71:185-193 (2009).

Kavamura MI, Peres CA, Alchorne MM, Brunoni D: CFC index for the diagnosis of cardiofaciocutaneous syndrome. Am J Med Genet 112: 12-16 (2002).

Koudova M, Seemanova E, Zenker M: Novel $B R A F$ mutation in a patient with LEOPARD syndrome and normal intelligence. Eur J Med Genet 52:337-40 (2009).

- Marino B, Digilio MC, Toscano A, Giannotti A, Dallapiccola B: Congenital heart diseases in children with Noonan syndrome: an expanded cardiac spectrum with high prevalence of atrioventricular canal. J Pediatr 135:703-706 (1999).

Martinelli S, De Luca A, Stellacci E, Rossi C, Checquolo $S$, et al: Heterozygous germline mutations in the $C B L$ tumor-suppressor gene cause a Noonan syndrome-like phenotype. Am J Hum Genet 87:250-257 (2010).

Nava C, Hanna N, Michot C, Pereira S, Pouvreau $\mathrm{N}$, et al: Cardio-facio-cutaneous and Noonan syndromes due to mutations in the RAS/ MAPK signalling pathway: genotype-phenotype relationships and overlap with Costello syndrome. J Med Genet 44:763-771 (2007).

Niihori T, Aoki Y, Narumi Y, Neri G, Cavé H, et al: Germline KRAS and BRAF mutations in cardio-facio-cutaneous syndrome. Nat Genet 38:294-296 (2006).

Noonan JA: Noonan syndrome. An update and review for the primary pediatrician. Clin $\mathrm{Pe}$ diatr (Phila) 33:548-555 (1994).

Nora JJ, Nora AH, Sinha AK, Spangler RD, Lubs HA: The Ullrich-Noonan syndrome (Turner phenotype). Am J Dis Child 127:48-55 (1974).

Nyström AM, Ekvall S, Berglund E, Björkqvist M, Braathen G, et al: Noonan and cardio-faciocutaneous syndromes: two clinically and genetically overlapping disorders. J Med Genet 45:500-506 (2008).

Pandit B, Sarkozy A, Pennacchio LA, Carta C, Oishi K, et al: Gain-of-function RAF1 mutations cause Noonan and LEOPARD syndromes with hypertrophic cardiomyopathy. Nat Genet 39:1007-1012 (2007).

Park MK: Pediatric Cardiology for Practitioners, ed 3, pp 34-51 (St. Louis, Mosby 1996).

Razzaque MA, Nishizawa T, Komoike Y, Yagi H, Furutani M, et al: Germline gain-of-function mutations in RAF1 cause Noonan syndrome. Nat Genet 39:1013-1017 (2007).
Rodriguez-Viciana P, Rauen KA: Biochemical characterization of novel germline BRAF and MEK mutations in cardio-facio-cutaneous syndrome. Methods Enzymol 438:277-289 (2008).

Roberts A, Allanson J, Jadico SK, Kavamura MI, Noonan J, et al: The cardiofaciocutaneous syndrome. J Med Genet 43:833-842 (2006).

Roberts AE, Araki T, Swanson KD, Montgomery KT, Schiripo TA, et al: Germline gain-offunction mutations in SOS1 cause Noonan syndrome. Nat Genet 39:70-74 (2007).

Sanchez-Cascos A: The Noonan syndrome. Eur Heart J 4:223-229 (1983).

Sarcozy A, Digilio MC, Dallapiccola B: Leopard syndrome. Orphanet J Rare Dis 3:13 (2008).

-Sarcozy A, Carta C, Moretti S, Zampino G, Digilio MC, et al: Germline BRAF mutation in Noonan, LEOPARD, and cardiofaciocutaneous syndromes: molecular diversity and associated phenotypic spectrum. Hum Mutat 30:695702 (2009).

Schubbert S, Zenker M, Rowe SL, Böll S, Klein C, et al: Germline KRAS mutations cause Noonan syndrome. Nat Genet 38:331-336 (2006).

Sharland M, Burch M, McKenna WM, Paton MA: A clinical study of Noonan syndrome. Arch Dis Child 67:178-183 (1992).

Shaw AC, Kalidas K, Crosby AH, Jeffery S, Patton MA: The natural history of Noonan syndrome: a long-term follow-up study. Arch Dis Child 92:128-132 (2007).

Tartaglia M, Mehler EL, Goldberg R, Zampino G, Brunner HG, et al: Mutations in PTPN11, encoding the protein tyrosine phosphatase SHP-2, cause Noonan syndrome. Nat Genet 29:465-468 (2001).

Tartaglia M, Kalidas K, Shaw A, Song X, Musat DL, et al: PTPN11 mutations in Noonan syndrome: molecular spectrum, genotype-phenotype correlation, and phenotypic heterogeneity. Am J Hum Genet 70:1555-1563 (2002).

Tartaglia M, Pennacchio LA, Zhao C, Yadav KK, Fodale V, et al: Gain-of-function SOS1 mutations cause a distinctive form of Noonan syndrome. Nat Genet 39:75-79 (2007).

Tidyman WE, Rauen KA: The RASopathies: developmental syndromes of Ras/MAPK pathway dysregulation. Curr Opin Genet Dev 19: 230-236 (2009).

van der Burgt I, Berends E, Lommen E, van Beersum S, Hamel B, Mariman E: Clinical and molecular studies in a large Dutch family with Noonan syndrome. Am J Med Genet 53:187191 (1994).

Zenker M, Buheitel G, Rauch R, Koenig R, Bosse $\mathrm{K}$, et al: Genotype-phenotype correlations in Noonan syndrome. J Pediatr 144:368-374 (2004).

Zenker M, Horn D, Wieczorek D, Allanson J, Pauli S, et al: SOS1 is the second most common Noonan gene but plays no major role in cardio-facio-cutaneous syndrome. J Med Genet 44:651-656 (2007). 